\title{
A method for estimating the economic contribution of resource-based tourism
}

\author{
by Len M. Hunt ${ }^{1}$, Wolfgang Haider², Peter C. Boxall ${ }^{3}$ and Jeff Englin 4
}

\begin{abstract}
Resource-based tourism is an important economic activity occurring on publicly owned forested lands in northern Canada. However, little is known about the economic contribution of this sector to the regions where it is located. This paper describes a method to estimate revenues generated by tourist operators from data sources that are primarily in the public domain. The method is illustrated with an examination of northern Ontario's resource-based tourism sites that are not accessible by road. This method estimates that the 1137 tourist sites of the region generated approximately $\$ 114$ million in revenues in 2000 . The analysis also estimated revenues for six sub-regions and for different types of operations that were segmented by accessibility and accommodation type. We found that revenues were much higher for sites in northwestern than in northeastern regions of Ontario, and that float plane-accessible sites commanded significantly greater revenues than did train- or boat-accessible sites.
\end{abstract}

Key words: resource-based tourism, revenues, use, method, criteria and indicators, supply

\section{RÉSUMÉ}

Le tourisme axé sur les ressources est une importante activité économique qui se produit sur les terrains forestiers appartenant à l'État dans le Nord canadien. Cependant, on sait peu de choses au sujet de la contribution économique de ces secteurs pour les régions où se situent ces terrains. Ce document décrit une méthode permettant d'estimer les recettes générées par les exploitants d’entreprises touristiques à partir des sources de données qui appartiennent principalement au domaine public. La méthode est illustrée par un examen des endroits touristiques axés sur les ressources du Nord de l'Ontario qui ne sont pas accessibles au moyen d'une route. Cette méthode estime que les 1137 endroits touristiques de la région ont généré des recettes d'environ 114 millions de dollars en 2000. L’analyse a également estimé les recettes de six sous-régions et de différents types d'exploitations segmentées selon le type d'accessibilité et de moyens d'accueil. Nous avons constaté que les endroits touristiques de la région du Nord-Ouest de l'Ontario généraient des recettes beaucoup plus élevées que ceux qui se trouvent dans la région du Nord-Est, et que les endroits accessibles par hydravion rapportaient des gains considérablement plus importants que les endroits accessibles par train ou bateau.

Mots-clés : tourisme axé sur les ressources, recettes, utilisation, méthode, critères et indicateurs, approvisionnement

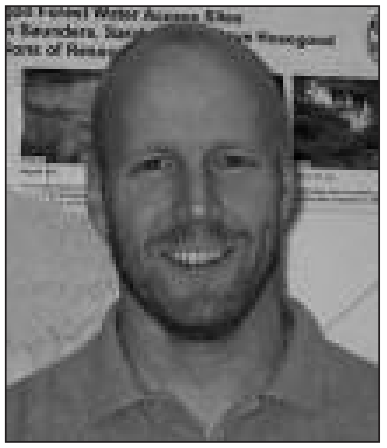

Len M. Hunt

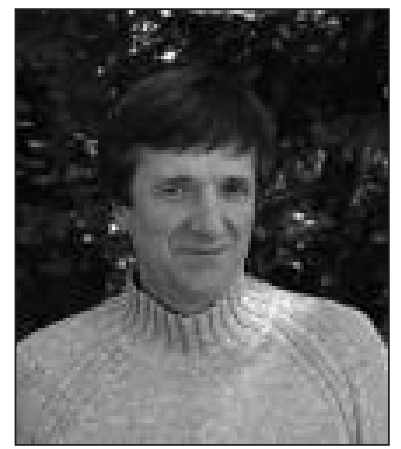

Wolfgang Haider

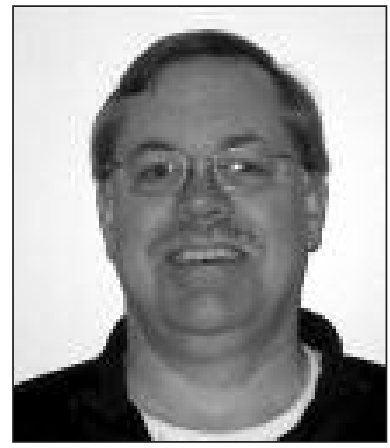

Peter C. Boxall

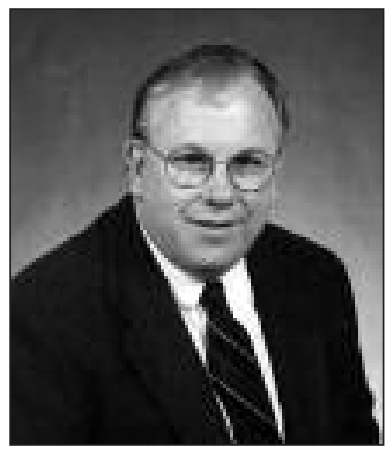

Jeff Englin

\footnotetext{
${ }^{1}$ Centre for Northern Forest Ecosystem Research, Ontario Ministry of Natural Resources, 955 Oliver Road, Thunder Bay, Ontario P7B 5E1. E-mail: len.hunt@mnr.gov.on.ca. Corresponding author.

${ }^{2}$ School of Resource and Environmental Management, Simon Fraser University, 8888 University Drive, Burnaby, British Columbia V5A 1S6. E-mail: whaider@sfu.ca

${ }^{3}$ Department of Rural Economy, University of Alberta, Edmonton, Alberta T6G 2H1. E-mail: peter.boxall@ualberta.ca

${ }^{4}$ The University of Nevada, Reno, Department of Resource Economics, College of Agriculture, Biotechnology and Natural Resources, Mail Stop 204, Reno, Nevada 89557-0105, USA. E-mail: englin@unr.edu
} 


\section{Introduction}

Canadian forests provide many economic opportunities for people who reside in or near them. While commercial forestry is an important industry, entertaining tourists is also an important economic use of forested settings. Despite its importance, little information and analysis exist about resource-based tourism.

Information on resource-based tourism can contribute to sustainable forest management in two ways. First, resource managers and others are increasingly aware that a healthy resource-based tourist sector helps to ensure that individuals and communities achieve a continual stream of benefits from forested environments. In fact, criteria and indicator frameworks for assessing sustainable forest management (e.g., OMNR 2002, CCFM 2003) require information on the economic contribution of non-timber related businesses. By measuring and monitoring information related to availability (i.e., supply), use and revenues, it is possible to assess the health of the resource-based tourism sector and its contribution to sustainable forest management.

The information is also required since the development of resource-based tourism may conflict with industrial operations that occur in forested settings. Tourist operations may require special regulations to mitigate impacts from industrial activities such as forestry (Ontario Ministry of Natural Resources 1987, 2001; McKercher 1992; Hunt et al. 2005a, b). These impacts on tourism may arise directly from forest harvesting (e.g., aesthetics) or indirectly from increasing numbers of other recreationists who respond to the improved access generated by forest access roads (e.g., recreational hunters and anglers).

An important research question in forest management is whether the costs of the additional protective measures that are required to sustain resource-based tourism are justified in terms of the benefits that tourism provides to provincial, regional and local economies. Information on resource-based tourism revenues can serve as a starting point for such a cost-benefit analysis.

Economic information about resource-based tourism is usually collected in expenditure surveys of tourists and occasionally revenue surveys of tourist operators (e.g., Topolinski and Anderson 1985, Hope Consulting Group 1987, The DPA Group 1988, Econometric Research Limited 1990, Research Strategy Group 1997, Pannell Kerr Forster 2003, Research Resolutions \& Consulting Ltd. 2003). Although this expenditure survey approach has a strong precedence, it is not without problems. One problem is the cost of collecting information. Surveys require a significant effort for their design, for the identification of a suitable population of individuals from which to sample, and for the implementation of the surveying process in a statistically rigorous manner.

A second problem with this method is the reliability of the information obtained from the surveys. Both non-response and recall biases (Dillman 2000) may affect the reliability of expenditure survey based data (Rylander et al. 1995) ${ }^{5}$. Nonresponse biases occur when respondents differ in important ways from non-respondents. This non-response bias is of particular concern when surveys achieve a low response rate.

\footnotetext{
${ }^{5}$ The type of survey instrument (e.g., interview) may also affect the reliability of expenditure survey responses (Bull et al. 2001).
}

Recall biases arise when individuals are asked to remember and record details about past behaviours (e.g., amount spent in restaurants). The level of detail required for accurate expenditure estimates often requires survey respondents to recall details on past expenditures, which individuals may have forgotten or at least recalled differently by the time of the interview. Recall and non-response biases can be minimized by contacting individuals prior to or immediately after taking a trip and by using Dillman's (2000) multiple contact approaches to obtain a high survey response rate. Essentially, the researcher needs to trade off reliability against higher survey costs.

A final issue is the potential for a strategic bias that may affect the expenditure estimates derived from the surveys. Although a strategic bias may occasionally affect responses by tourists, it is likely a serious issue with businesses who regard information about expenditures and revenues as confidential. While some government regulations require owners to provide exactly the same information (e.g., corporate tax), many owners may not be willing to provide these data to researchers. Thus, expenditure surveys sent to businesses or tourists may be either subject to non-response biases, or if the respondents perceive an advantage in over- or under-reporting expenditures and revenues, the information reported may be inaccurate.

We describe an alternate method for estimating the revenues generated by resource-based tourism that is inexpensive, simple, accurate and easy to scale up or down. The proposed method only requires information or estimates of the number of tourist sites, the supply of available accommodation, the prices charged at the sites, and the use levels at the sites. Detailed descriptions of tourist sites, the prices charged, and many other potentially important characteristics are usually freely available from tourist brochures and Web sites that operators use to advertise their sites and products. Information on occupancy rates must come from primary (i.e., operator interviews) or secondary (e.g., reports from other tourism studies, tourism associations) sources. After collecting all relevant data, it is straightforward to estimate revenues and use levels for specific tourist sites and compile the estimates by various criteria, depending on the purpose of analysis.

To illustrate the method, an empirical application is presented for one specific resource-based tourism product in northern Ontario for the year 2000. This case study is limited to fixed-roofed tourist accommodation sites in northern Ontario that are not accessible by road. The homogeneity in products offered by these sites compared to those offered by their road-accessible counterparts make non-road-accessible tourist sites ideal for demonstrating the method. One could easily expand the method to any other tourism product such as road-accessible tourist sites by adding further assumptions to make the sites sufficiently comparable.

To estimate the economic contribution of non-road-accessible tourism, we require measures or estimates of capacity (i.e., supply), use, and revenue generation of the individual sites, which can then be aggregated during analysis by various criteria such as site accessibility, accommodation type and location. It is well established that these three criteria affect the resource-based tourism product strongly (Haider and Hunt 1997, Hunt et al. 2005b). Float plane, boat and train accessibility types comprise the non-road-accessible tourism 
sites. Revenues should differ among these accessibility types due to varying costs of transporting guests and the high value of remoteness achievable at float plane-accessible sites.

Revenues may also differ due to the accommodation type. For this study, we distinguish two accommodation types: a lodge has a reception area and additional amenities (e.g., restaurant/bar) along with many rooms or cabins for guests. These lodges may offer American Plan packages that include all meals, or housekeeping packages where guests provide their own food. Outpost camps, by contrast, offer a secluded cabin with few amenities. The differences in the capacity of the facility along with differences in the amenities provided will result in different revenues generated among lodge and outpost camp accommodations.

Finally, the location of the tourist site is also likely to command differences in prices. Hunt et al. (2005a) found that prices for week-long fishing packages increase as one moves north and west across northern Ontario with a peak in the Lac Seul area (see Fig. 1). The prices charged by operators may be two times higher in the Lac Seul area compared to some areas within northeastern Ontario. The reasons for these spatial differences in prices are generally not well understood although the different availability of water bodies, preferred fish species and the types and levels of amenities at sites may explain some of this price variation.

The next section describes the data collected to estimate the revenues. The third section outlines the data preparation required to estimate use levels and revenues. The results are presented in the fourth section. Finally, the discussion focuses on the application of the revenue estimation method and the managerial significance of the case study employed to showcase the applicability of the method.

\section{Data}

The data for this case study were collected from several sources. We attempted to enumerate the number of nonroad-accessible tourism sites in northern Ontario from incomplete government databases and searches of tourist brochures and Web sites. These Web site searches involved the use of key words of lodges, resorts and outposts and searches for specific lakes or establishment names when secondary sources (e.g., tourism associations) listed various tourism establishments. From these efforts, it was estimated that 1138 non-road-accessible tourist sites operated in northern Ontario in $2000^{6}$. This estimate closely matches an Ontario-wide estimate of 1400 float plane-, boat- and trainaccessible sites for 1996 that also included sites with controlled road access (Research Strategy Group 1997).

\footnotetext{
${ }^{6}$ Because of our interest in separating the resource-based tourism along accessibility, accommodation and regional themes, one float plane-accessible lodge, which would have been the sole representative in one region, was omitted from analysis for confidentiality reasons.
}

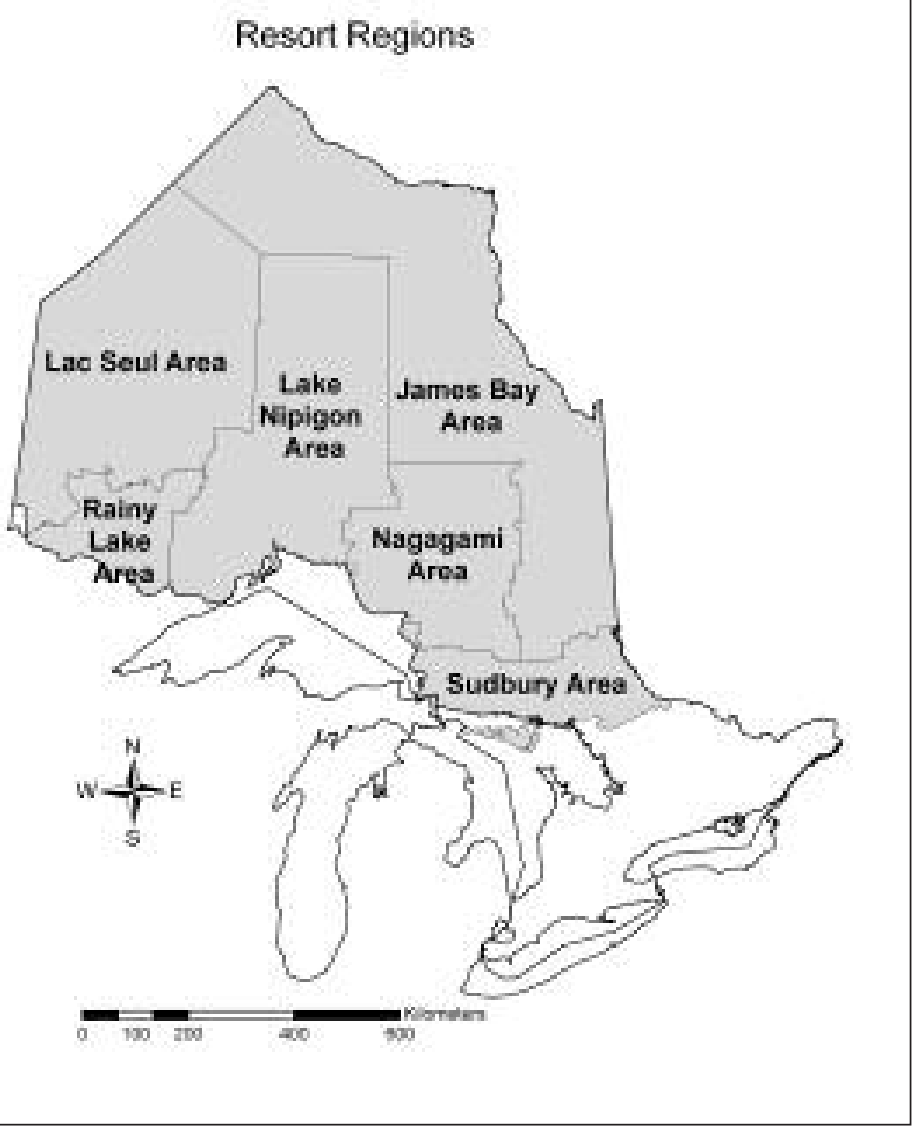

1. Regions of northern Ontario.

Tourist brochures and Web sites contained plenty of relevant information about the tourist sites, such as ownership, exact location, mode of access, and a precise description of the types of accommodation offered. We determined that there were 344 individuals who owned and operated one or more of these 1138 sites. Prices for week long fishing trips to the sites were also frequently published in these promotional materials. Finally, the brochures and Web sites also contained a wealth of additional information about fish species and game, amenities associated with the site, and ownership structure.

We used the database of these 1138 tourist sites to administer a simple and relatively short mail survey to tourist operators. The main purpose of the survey was to collect information for a hedonic price analysis of the effects of forest harvesting on resource-based tourism in Ontario (see Hunt et al. 2005a, b for details). The survey also solicited information about occupancy rates and all recreation opportunities available to tourists at the various sites. We purposely avoided questions about revenues or expenditures, which would likely have decreased the response rate. Following the multiple contact principle (Dillman 2000), we sent pre-notice letters, a survey, a postcard reminder, a second survey and an e-mail reminder to the operators. To increase response rates further, a draw for an annual Northern Ontario Tourist Outfitter Association membership was offered as an incentive. Of the 
344 surveys distributed to operators ${ }^{7}, 218$ were returned with complete information for a final response rate of $63.4 \%$. By focusing on tourism operators and simplifying the response task (e.g., occupancy instead of all revenues and expenditures), this survey limited non-response bias. By contrast, studies asking for expenditures by tourists (Research Strategy Group 1997) and tourism operators (Pannell Kerr Forster 2003) in northern Ontario achieved response rates of only $17 \%$ and $6 \%$, respectively.

We believe that the occupancy rate information provided by the operators does not suffer from a strategic bias. If operators over-reported their occupancy estimates, there would be little evidence that forestry activities impact their tourism operations. Conversely, if operators under-reported their occupancy rates, the resource-based tourism product would appear as a rather unimportant economic activity. Without an obvious advantage to under- or over-report this information, it is believed that the tourism operators reported accurate occupancy rate information. Finally, asking tourism operators to provide information on occupancy limits recall biases as operators will have records of this information.

\section{Data Preparation}

Fig. 2 shows that only four variables (bed capacity, seasonal operation, occupancy rates, and prices charged) are required to estimate the economic contribution of tourism. With these four variables, it is straightforward to derive estimates of total bed capacity (i.e., supply), bed capacity use, and revenues. This section describes the various assumptions underlying the data preparation.

Our commitment to confidentiality and the necessity of using some simplifying assumptions, mostly to make the data comparable, led us to report aggregated results on the basis of regions, levels of accessibility and accommodation type. To ensure a reasonable minimum number of tourist sites in each region, the administrative Districts of the Ontario Ministry of Natural Resources in northern Ontario were aggregated into six regions. These regions, shown in Fig. 1, include: Lac Seul (Kenora, Red Lake and Sioux Lookout Districts); Rainy Lake (Dryden and Fort Frances Districts); Lake Nipigon (Nipigon and Thunder Bay Districts); Nagagami (Chapleau, Hearst and Wawa Districts); James Bay (Cochrane, Kirkland Lake, and Timmins Districts) and Sudbury (North Bay, Sault Ste. Marie, and Sudbury).

For every region, separate estimates were derived for each accessibility and accommodation type. The train- and boataccessible sites were merged because of the small number of train-accessible sites. For accommodation, only outpost camps and lodges were considered in this analysis, effectively omitting other tourist ventures such as canoe outfitters, who use predominantly transient forms of accommodation. Based on these assumptions, four accessibility and accommodation site types were examined for each region: fly-in outpost camps, fly-in lodges, boat or train outpost camps, and boat or train lodges.

A crucial data variable was the total supply of bed nights that each tourist site could have served in the year 2000. This

\footnotetext{
${ }^{7}$ The discrepancy between 344 operators as the sampling population and 1138 sites is explained by many operators owning multiple tourist sites.
}

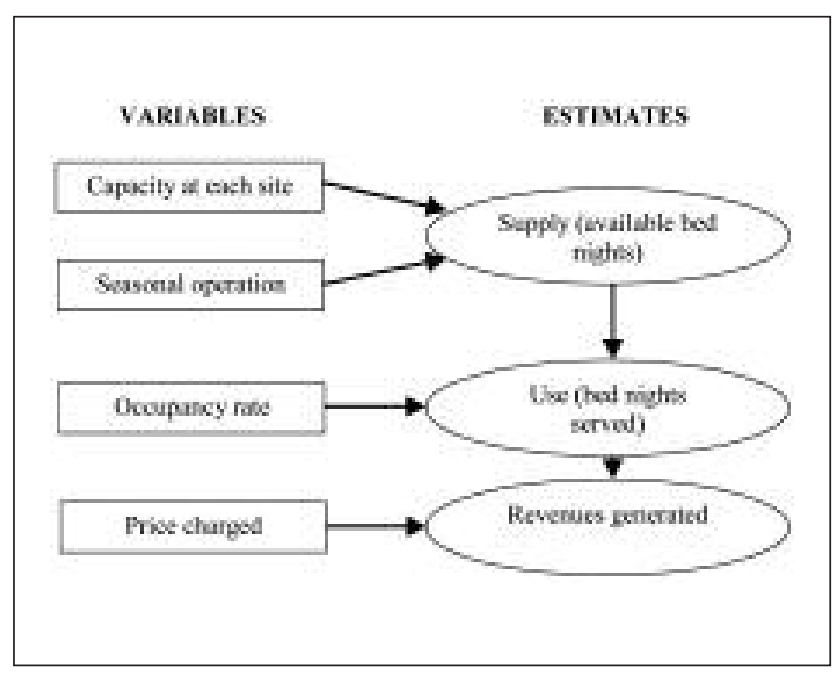

Fig. 2. Data sources required for analysis.

supply estimate was derived from the capacity of each site multiplied by the number of nights that the site was in operation in 2000 (see Fig. 2). For outpost camps, the median capacity ranged from 6.0 to 9.5 guests and from 18.0 to 21.5 weeks for length of season for most regions. By contrast, the lodges had median capacities ranging from 20 to 39 units and median weeks of operation between 19 and 20 weeks. The values for the few sites with missing information were set equal to the median values for the respective region and site type.

Along with an estimate of the available supply, the analyses also required an estimate of the actual number of nights spent by tourists at these sites in 2000. This occupancy information was estimated from the survey responses, where operators were asked two different questions related to occupancy. First, we simply asked for the site's occupancy rate for the year 2000. Second, we asked for the number of person nights served by the tourist site. While it was expected that both measures would reliably measure occupancy, in reality the two measures differed markedly in their estimates. To understand the differences, we discussed the issue with many tourism operators. These discussions led to the conclusion that the difference arose from a different interpretation of the concept of occupancy between the researchers and most tourist operators. Our definition of an occupancy rate is the percentage of all available bed nights actually sold by a tourist site. For many operators, however, this definition makes no practical sense. When an operator rents an eight-person cabin to a party of four guests, she cannot add other guests to this cabin, and therefore, the operator would conclude that the cabin is $100 \%$ occupied. Our need for occupancy rates based on the use of all available bed nights limited the response to the occupancy rate data to only 236 sites. To implement the model, we assumed that every region would have the same occupancy rate for a given accessibility and accommodation type.

Using these assumptions, the mean estimated occupancy rates were $30.5 \%, 30.7 \%, 22.1 \%$, and $27.6 \%$ for float planeaccessible outpost camps, lodges, and boat/train-accessible outpost camps and lodges, respectively. These rates appear 
low simply because of our definition of occupancy. If we used an operator's definition of occupancy (i.e., whether a cabin is occupied or not), the estimates of occupancy would be much greater (e.g., the estimated occupancy rates as defined by tourism operators was about $60 \%$ for float plane accessible outpost camps and lodges (Hunt et al. 2002)).

Fig. 2 shows that price and use information is needed to estimate revenues. However, we found that operators charged different prices depending on the activity focus of the guests and for lodges the type of meal plan. One survey question asked operators about the proportions of their guests that pursued different activities. This question listed activities of fishing less than a week, fishing for a week or more, moose hunting, other hunting and non-consumptive uses. Most person nights (about 90\%) were associated with fishing. A more detailed examination of the actual number of days included in advertised packages revealed that fishing trips of one week or more typically consisted of seven nights, while fishing trips of less than one week typically included four nights. Hunting and other trips, which occurred much less frequently, were assumed to be of one week in duration.

The prices were determined from survey, Web site, and brochure information and were standardized for a sevenday fishing trip. These seven-day fishing trip packages were standardized to Canadian dollars before taxes by using the average exchange rate for the US Dollar (i.e., 0.6487 American) over the primary tourist season from May 18 to Sept. 5, 2000. Since the prices for packages other than week-long fishing trips were not readily available for all sites, these prices were determined as proportions of the prices for week-long fishing trips. For float plane-accessible sites, a sample of 491 sites revealed that fourday fishing prices averaged $78.9 \%$ of the cost of a seven-day price. At boat- or train-accessible sites, a sample of 43 sites revealed four-day fishing prices averaged $62.4 \%$ of the cost of a seven-day price. For non-fishing packages, it was assumed that seven-day moose hunting prices were two times, other hunting prices were 1.5 times, and other trips were 0.75 times the week-long price of a fishing package. These estimates were based on a small set of comparisons of prices for these various packages. These ratios were held constant for all regions and accommodation types.

Lodges may offer housekeeping and/or American Plan meal options. In cases where lodges offered both American Plan and housekeeping packages, the revenue estimate required information on the percentage of guests who paid for housekeeping and American Plan packages at these lodges. Without any other information, it was assumed that the proportion of guests paying for housekeeping packages would equal the number of purely housekeeping plan packages divided by the number of lodges offering either purely housekeeping or American Plan packages. This assumption led to estimates of $59.2 \%$ and $59.3 \%$ of guests paying for housekeeping packages at float plane- and boat- or train-accessible lodges, respectively.

\section{Results}

The above data and assumptions allowed us to estimate the potential capacity, levels of use and revenue of non-roadaccessible resource-based tourism sites in northern Ontario for the year 2000. We present the results in four tables, one for each possible combination between access and accommodation types: float plane-accessible outpost camps (FP-OC) and lodges (FP-LO) and boat- or train-accessible outpost camps (BT-OC) and lodges (BT-LO). In each table, the columns contain the crucial elements of information required to derive the tourism revenue estimates. The rows list the information for the respective regions, and summarize it for all of north-

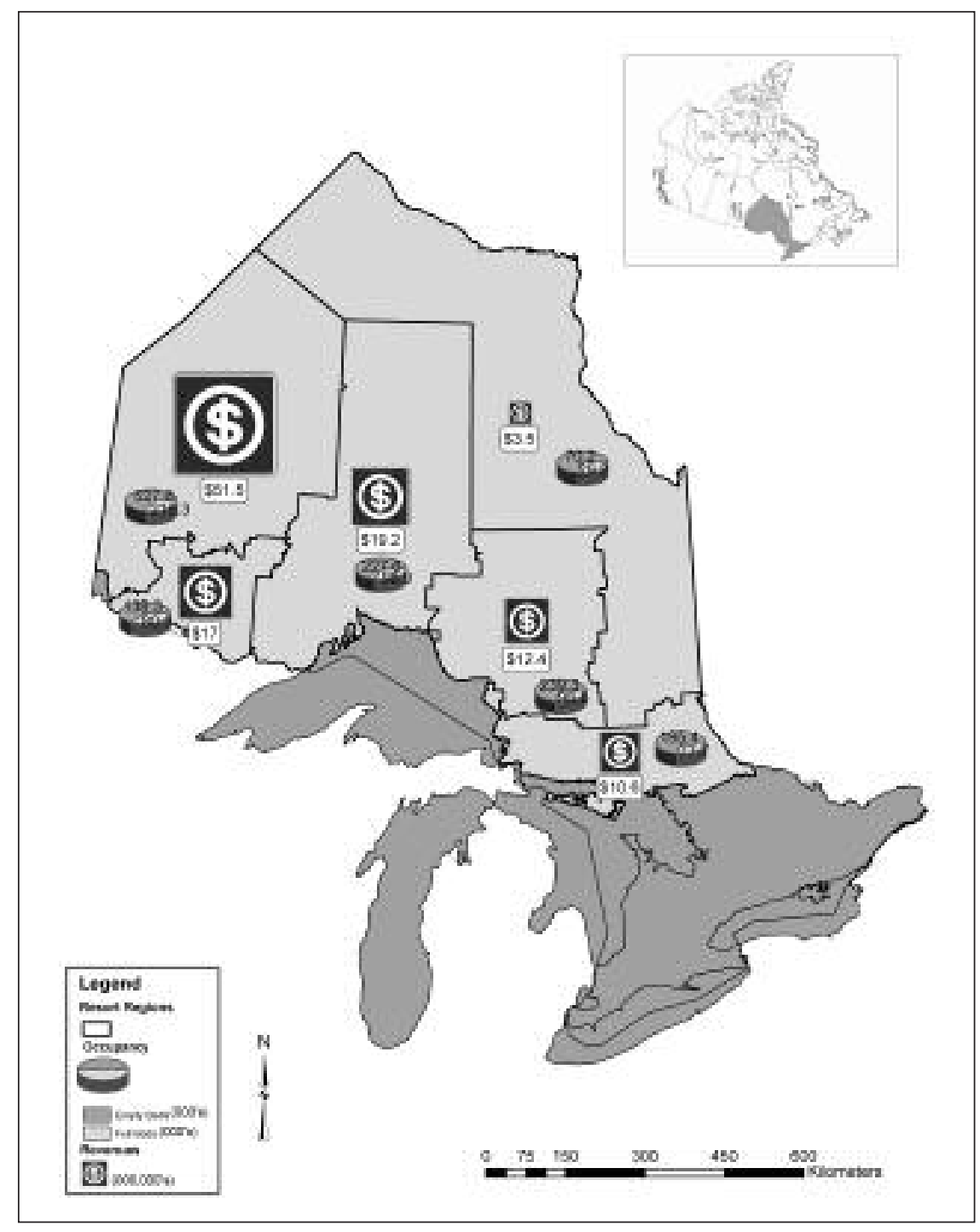

Fig. 3. Summary of tourism statistics in different regions of northern Ontario, २०००. 
Table 1. Summary estimates of capacity and revenues for float plane accessible outpost camps

\begin{tabular}{|c|c|c|c|c|c|c|}
\hline Region & $\begin{array}{c}\text { Total Capacity } \\
\text { (000s) }\end{array}$ & $\begin{array}{l}\text { Use } \\
(000 s)\end{array}$ & $\begin{array}{c}\text { Revenues } \\
(\$ 000,000 \mathrm{~s})\end{array}$ & $\begin{array}{l}\text { Revenue/bed } \\
\text { (\$000s) }\end{array}$ & $\begin{array}{l}\text { Revenue/site } \\
\quad(\$ 000 \mathrm{~s})\end{array}$ & Sites \\
\hline Lac Seul & 274.3 & 83.7 & $\$ 17.7$ & $\$ 8.5$ & $\$ 68.5$ & 258 \\
\hline Rainy Lake & 86.2 & 26.3 & $\$ 5.3$ & $\$ 8.1$ & $\$ 65.2$ & 81 \\
\hline Lake Nipigon & 188.5 & 57.5 & $\$ 10.9$ & $\$ 7.1$ & $\$ 60.2$ & 181 \\
\hline Nagagami & 136.3 & 41.6 & $\$ 4.5$ & $\$ 4.8$ & $\$ 35.0$ & 128 \\
\hline James Bay & 75.3 & 23.0 & $\$ 2.8$ & $\$ 4.6$ & $\$ 32.0$ & 89 \\
\hline Sudbury & 74.0 & 22.6 & $\$ 2.5$ & $\$ 4.4$ & $\$ 34.0$ & 74 \\
\hline Totals/Averages & 835 & 254.8 & $\$ 43.7$ & $\$ 6.8$ & $\$ 53.9$ & 811 \\
\hline
\end{tabular}

Table 2. Summary estimates of capacity and revenues for float plane accessible lodges

\begin{tabular}{|c|c|c|c|c|c|c|}
\hline Region & $\begin{array}{c}\text { Total Capacity } \\
\text { (000s) }\end{array}$ & $\begin{array}{l}\text { Use } \\
(000 s)\end{array}$ & $\begin{array}{c}\text { Revenues } \\
(\$ 000,000 \mathrm{~s})\end{array}$ & $\begin{array}{c}\text { Revenue/bed } \\
\quad(\$ 000 \mathrm{~s})\end{array}$ & $\begin{array}{l}\text { Revenue/site } \\
\quad(\$ 000 s)\end{array}$ & Sites \\
\hline Lac Seul & 134.6 & 41.4 & $\$ 11.9$ & $\$ 10.7$ & $\$ 331.3$ & 33 \\
\hline Rainy Lake & 54.5 & 16.8 & $\$ 4.1$ & $\$ 10.5$ & $\$ 375.0$ & 11 \\
\hline Lake Nipigon & 112.9 & 34.8 & $\$ 7.6$ & $\$ 8.8$ & $\$ 231.3$ & 33 \\
\hline Nagagami & 73.1 & 22.5 & $\$ 3.9$ & $\$ 7.5$ & $\$ 280.8$ & 14 \\
\hline James Bay & RS & RS & RS & RS & $\mathrm{RS}$ & $\mathrm{RS}$ \\
\hline Sudbury & 23.0 & 7.1 & $\$ 1.1$ & $\$ 6.5$ & $\$ 142.7$ & 8 \\
\hline Totals/Averages & 398.0 & 122.6 & $\$ 28.6$ & $\$ 9.3$ & $\$ 288.9$ & 99 \\
\hline
\end{tabular}

RS - one lodge was removed from all analysis to ensure the anonymity of that operation

Table 3. Summary estimates of capacity and revenues for train or boat accessible outpost camps

\begin{tabular}{|c|c|c|c|c|c|c|}
\hline Region & $\begin{array}{c}\text { Total Capacity } \\
(000 \mathrm{~s})\end{array}$ & $\begin{array}{l}\text { Use } \\
(000 s)\end{array}$ & $\begin{array}{c}\text { Revenues } \\
(\$ 000,000 s)\end{array}$ & $\begin{array}{l}\text { Revenue/bed } \\
\quad(\$ 000 s)\end{array}$ & $\begin{array}{c}\text { Revenue/site } \\
\text { (\$000s) }\end{array}$ & Sites \\
\hline Lac Seul & 24.2 & 5.3 & $\$ 0.5$ & $\$ 3.3$ & $\$ 27.3$ & 20 \\
\hline Rainy Lake & 31.4 & 6.9 & $\$ 0.8$ & $\$ 3.8$ & $\$ 31.0$ & 25 \\
\hline Lake Nipigon & 7.3 & 1.6 & $\$ 0.1$ & $\$ 2.3$ & $\$ 15.8$ & 7 \\
\hline Nagagami & 19.7 & 4.4 & $\$ 0.3$ & $\$ 1.9$ & $\$ 13.8$ & 20 \\
\hline James Bay & 7.1 & 1.6 & $\$ 0.1$ & $\$ 1.1$ & $\$ 10.5$ & 6 \\
\hline Sudbury & 10.0 & 2.2 & $\$ 0.1$ & $\$ 1.4$ & $\$ 14.6$ & 9 \\
\hline Totals/Averages & 100.0 & 22.0 & $\$ 1.9$ & $\$ 2.7$ & $\$ 21.8$ & 87 \\
\hline
\end{tabular}

Table 4. Summary estimates of capacity and revenues for train or boat accessible lodges

\begin{tabular}{|c|c|c|c|c|c|c|}
\hline Region & $\begin{array}{c}\text { Total Capacity } \\
\text { (000s) }\end{array}$ & $\begin{array}{l}\text { Use } \\
(000 s)\end{array}$ & $\begin{array}{c}\text { Revenues } \\
(\$ 000,000 s)\end{array}$ & $\begin{array}{c}\text { Revenue/bed } \\
\text { (\$000s) }\end{array}$ & $\begin{array}{l}\text { Revenue/site } \\
\quad(\$ 000 s)\end{array}$ & Sites \\
\hline Lac Seul & 310.8 & 85.8 & $\$ 21.4$ & $\$ 9.5$ & $\$ 362.5$ & 59 \\
\hline Rainy Lake & 109.5 & 30.2 & $\$ 6.8$ & $\$ 9.3$ & $\$ 323.7$ & 21 \\
\hline Lake Nipigon & 17.8 & 4.9 & $\$ 0.6$ & $\$ 4.0$ & $\$ 80.3$ & 7 \\
\hline Nagagami & 108.7 & 30.0 & $\$ 3.7$ & $\$ 4.8$ & $\$ 159.5$ & 23 \\
\hline James Bay & 17.0 & 4.7 & $\$ 0.6$ & $\$ 5.0$ & $\$ 186.5$ & 3 \\
\hline Sudbury & 166.1 & 45.9 & $\$ 6.9$ & $\$ 6.5$ & $\$ 257.1$ & 27 \\
\hline Totals/Averages & 730.0 & 201.5 & $\$ 39.9$ & $\$ 7.8$ & $\$ 285.7$ & 140 \\
\hline
\end{tabular}


ern Ontario in the final row. Finally, a map (Fig. 3) summarizes the overall revenue generation of these types of resourcebased tourism in northern Ontario.

Table 1 summarizes the estimated values for float plane accessible outpost camps (FP-OC) on capacity, person night use, revenues, revenues per site and revenues per bed. It was estimated that the 811 FP-OCs offered a total of 835000 bed nights during the typical 20-week-long season for the year 2000. Of these, an estimated 254800 bed nights were actually sold for an occupancy rate of $30.5 \%$. These guest nights generated approximately $\$ 43.7$ million in revenues in 2000 with an average site generating revenues of $\$ 53900$. Each bed in an average FP-OC was estimated to generate $\$ 6800$ in revenues.

While these totals and average estimates for northern Ontario are interesting, they mask the fundamental differences among the six regions. The region-specific estimates suggested that FP-OC sites in the western regions (Lac Seul and Rainy Lake) generated almost twice the revenue per site (over $\$ 65000$ ) than did sites (about $\$ 35$ 000) in eastern areas (Nagagami, James Bay and Sudbury). Since the basis for this calculation is revenue per bed, one cannot explain these regional differences by the differences in number of sites between the regions. The number of FP-OC sites was also substantially higher in the Lac Seul region than in any other region, adding further to the overall importance of tourism in this region compared to the others.

Table 2 shows the same set of estimates for the 99 float plane-accessible lodges (FP-LO). Clearly, there were many more FP-OC sites than there were FP-LO sites. Although the use estimates at FP-LO sites (122 600) were approximately half the estimated total nights at FP-OC sites (254 800), the estimated total revenue for FP-LO sites (\$28.6 million) was about two-thirds of that generated at the FP-OC sites $(\$ 43.7$ million). This discrepancy was attributable to the greater capacity found in lodges than in outpost camps. The higher estimates for revenues per bed for this product (\$9300) compared to FP-OC sites (\$6800) also suggested that FP-LO sites were able to extract greater revenue from their capacity than were FP-OC sites.

The same geographical differences that were found for the FP-OC sites existed for FP-LO sites. Locations in western areas of northern Ontario generated much higher revenues per bed (over $\$ 10$ 000) than did those lodges in eastern areas (under \$8000). It was estimated that the combined revenues of lodges in the Lac Seul and Rainy Lake regions (\$16 million) were over three times the combined revenues of lodges in the James Bay and Sudbury regions (\$5 million). Although a lodge in the Lake Nipigon region was estimated to produce less revenue (\$231 300) than a lodge in the Nagagami region (\$280 800), the Lake Nipigon region lodges were estimated to have generated greater revenues per bed $(\$ 8800)$ than did the Nagagami region lodges (\$7500).

The next table (Table 3 ) displays estimates for the 87 boator train-accessible outpost camps (BT-OC). The estimated totals and averages suggested that this form of tourism generated much less revenue ( $\$ 1.9$ million) than did FP-OCs ( $\$ 43.7$ million) or FP-LOs (\$28.6 million). On average, a BT-OC site was estimated to generate about $\$ 4000$ less in revenue per bed than an average FP-OC site. While some of this revenue difference reflects differences in costs of transporting guests between these forms of tourism, it is believed that a premium exists for float plane accessible sites because of higher expectations of remoteness at these sites (Hunt et al. 2005b). The number of BT-OC sites was also small when compared to FP$\mathrm{OC}$ sites. These facts suggest that there was a much stronger demand for float plane- than for boat- or train-accessible outpost camps.

Again, the revenue estimates for BT-OC sites were different among the various regions in northern Ontario with the Lac Seul and Rainy Lake region sites generating more than two times the expected per bed revenue (over \$3000) than did sites in the James Bay and Sudbury regions (under \$1500). The revenues per bed were estimated to be greatest in the Rainy Lake (\$3800) rather than in the Lac Seul region (\$3300). This difference from the same estimates for the float plane-accessible sites may relate to the long travel costs that guests who used the more northerly Lac Seul area sites may have incurred compared to guests who traveled to the Rainy Lake area. These increased transport costs may also have curbed the demand for such BT-OC trips to the Lac Seul area as evidenced by the fewer sites in the Lac Seul (20) than the Rainy Lake region (25).

The set of estimates for the 140 boat- or train-accessible lodges (BT-LO) are provided in Table 4. An average BT-LO site was estimated to generate about the same revenues (\$285 700) as an average FP-LO site (\$288 900). As well, these BT-LO sites were estimated to produce more total revenue (\$39.9 million) than did FP-LO sites (\$28.6 million). These surprising facts arose from the greater capacity that these BT-LO sites have compared to FP-LO sites as evidenced by the lower per-bed revenues at BT-LO (\$7800) when compared to FP-LO sites (\$9300). There were also more BT-LO sites than there were FP-LO sites in northern Ontario.

The regional estimates suggested that the highest revenue producing BT-LO sites were located in the Lac Seul and Rainy Lake regions with estimates of greater than $\$ 9000$ per bed. The lower than expected BT-LO revenue estimate of $\$ 4000$ per bed for sites in the Lake Nipigon area was likely a result of the few sites that offered these accommodations in this region.

In summary, our method estimated that the fixed accommodation, non-road-accessible tourism sector of northern Ontario sold approximately 600000 of the 2000000 available bed nights at 1137 non-road-accessible tourism sites in the year 2000. These guests were estimated to have paid tourist operators a total of approximately \$114 million CDN.

The map in Fig. 3 summarizes this economic information from the previous tables for the six regions. The Lac Seul region alone accounted for over one third of the guest nights (216 300) and generated almost 50\% of total resource-based tourism revenues ( $\$ 51.5$ million) in northern Ontario. The three most easterly regions by contrast did not generate onequarter of the revenues ( $\$ 26.5$ million) despite offering over one-third of all tourist sites (401). While the total revenue contribution of the Rainy Lake region ( $\$ 17$ million) was much lower than that for Lac Seul region (\$51.5 million), this difference was almost entirely attributable to the large difference in the number of sites between these regions (370 compared to 138 sites). In fact, estimated revenues per site were fairly similar between these two regions. 


\section{Discussion and Conclusion}

Managers of public forest lands must carefully balance conflicts between forest users such as the forest industry and resource-based tourism. To balance both uses on the landbase, regular forestry operations are often adjusted to minimize the conflict between these two forest uses. However, managers require some understanding of the economic relevance of resource-based tourism for local, regional and provincial economies to justify any increased forestry operational costs resulting from greater protection measures for resource-based tourism.

Economic and use information is also increasingly required by monitoring approaches related to forest sustainability (OMNR 2001, CCFM 2003). These approaches suggest that a healthy tourist sector is an important element in ensuring that Canadians achieve a continual stream of economic benefits from use of forested environments. As such, there are needs to establish baseline economic conditions for resourcebased tourism and to monitor these conditions into the future. However, little if any information exists about the economic health of the resource-based tourism sector in Canada.

Expenditure surveys of tourists or tourist operators are frequently employed to gather such economic information. While expenditure surveys provide useful information, these surveys are expensive to administer when reliable estimates for many categorizations of tourism (e.g., different geographies, different accessibilities) are required. For this reason, we developed and illustrated a method to estimate resourcebased tourism revenues from data sources that are primarily in the public domain. This approach also allows one to estimate revenues and the use levels at individual tourism sites or any category based on spatial, activity type, or accommodation type aggregates. This ability to define spatial units may be especially relevant when individuals are asked to produce summary information about resource-based tourism for geographies such as forest management units. If the data used for the analysis here were collected on a routine basis, it would be simple to estimate the contribution of the various tourism sectors.

The data employed by the analyst will affect the precision of any resulting estimates. At an extreme, one could obtain crude estimates of revenues for resource-based tourism sites by using secondary data sources to estimate occupancy rates and activity pursuits of guests while having specific information about prices and capacity. Under this extreme, no data beyond freely available brochure and Web site information on resource-based tourism sites are needed. At another extreme ${ }^{8}$, one could survey tourist operators and obtain sitespecific occupancy and revenue information.

Our application of northern Ontario tourist sites chose a middle ground between these two extremes. A survey of tourist operators was conducted to estimate occupancy rates and activity pursuits of guests. However, we used average occupancy rates for tourist sites that differed by accessibility and accommodation type. The use of partially aggregated data for use and activity pursuits was warranted because of

\footnotetext{
${ }^{8}$ One could simply require through regulation that tourism operators provide information about the number of guests and their activity pursuits. While data from this approach will be very reliable at even an individual operational level, the approach requires considerable will and substantial support from the tourism industry.
}

our focus on estimating revenues and use among tourist sites aggregated by regions, accessibility and accommodation. The partial aggregation of occupancy rate information also helped to reduce the likelihood that any incorrect information provided by any tourist operator would affect the results.

Resource-based tourism can generate considerable revenue for tourist operators. In fact, it was estimated that in 2000 the approximately 600000 tourist nights generated over $\$ 114$ million dollars for operators of non-road-accessible tourist sites in northern Ontario. These estimates are much lower than the $\$ 183$ million in expenditures and approximately one million guest nights estimated by the Research Strategy Group (1997) for Ontario's remote tourism operations in 1996. The estimates from Research Strategy Group, however, included extra tourism sites (i.e., some road-accessible sites) and tourist expenditures (e.g., transportation to Ontario) rather than tourism operator revenues. The differences in estimates may also arise from non-response bias as the Research Strategy Group estimates were based on a 17\% response rate from tourists staying at about one-third of all remote tourism establishments.

One can use our revenue estimates to determine economic impacts at various geographies ${ }^{9}$. This assessment of economic impacts could describe the importance of resource-based tourism to the economies of various geographies (e.g., communities, regions).

The analyses also showed that resource-based tourism revenues are affected heavily by geography and accessibility. The regional analyses showed that sites located in the northwest regions of Ontario were estimated to generate revenues in excess of two to three times the revenues of sites in northeast regions. Investigating the reasons for these differences may assist in identifying strategies that enhance the northeast tourist sites and in identifying suitable sites for tourism expansion. Some reasons that may contribute to the differences in revenues among the regions include different market areas, greater availability of preferred species for consumptive activities, differences in the supply of good quality lakes, greater levels of investment in the tourist facilities and greater potential for conflict with road-based anglers and other recreationists in the more populous eastern areas of northern Ontario.

As with the regional analyses, huge differences in revenues were estimated between sites accessible by float plane and sites accessible by train or boats. The revenues for float planeaccessible outpost camps were almost three times the estimated revenues at boat- or train-accessible outpost camps (\$49 100 to $\$ 18800$ ). This difference is important for resource managers as any actions that jeopardize the viability of float plane outpost camps or lodges may drastically reduce resource-based tourism revenues in a region.

Like any method, the proposed method has several limitations. First, the validity of the revenue and use estimates depends on the accuracy of input data. Any errors on the number of establishments, weeks of operation, capacity, price and occupancy rates will affect estimates from this method. Second, while most input data are accessible, occupancy rate information may be difficult to obtain. The use of survey instruments to estimate occupancy rates are potentially sub-

${ }^{9}$ One could also include information about expenditures made by tourists that are not paid to tourist operators (e.g., vehicle fuel). 
ject to survey-based errors and increased costs. Third, several assumptions are used to allocate tourists among activity and meal packages with different prices. If these assumptions are wrong, the estimates will suffer. Finally, it is difficult to establish confidence bounds on any estimates. However, assessing the estimates under different assumptions will provide some assessment of the sensitivity of the estimates to specific assumptions.

\section{Acknowledgements}

We thank the Ontario Ministry of Natural Resources and the Northern Ontario Tourist Outfitters Association for helping to fund the research. Mandie Ross, Sarah Browne and Karen Saunders are also thanked for their contributions with inventorying tourism sites and preparing figures. We also thank an anonymous reviewer for constructive suggestions that have helped to improve the paper.

\section{References}

Bull, A., M. Walo and H. Breen. 2001. A comparison of survey methods to estimate visitor expenditure at a local event. Tour. Man.: 22(5): 473 - 497.

Canadian Council of Forest Ministers (CCFM). 2003. Defining sustainable forest management in Canada: criteria and indicators. Canadian Council of Forest Ministers, Ottawa, ON. 21 p.

Dillman, D.A. 2000. Mail and internet surveys: the tailored design method. John Wiley and Sons, Inc., Toronto, ON. 464 p.

Econometric Research Ltd. 1990. Economic impact of the remote tourism industry. Ont. Min. Tour. Recreat., Toronto, ON.

Haider, W. and L.M. Hunt. 1997. Remote tourism in northern Ontario: patterns of supply and a motivational segmentation of clients. J. Applied Recr. Resear. 22(1): 49-78.

Hope Consulting Group. 1987. Red Lake/Golden: economic impact of tourism. Ont. Min. Tour. Recreat.

Hunt, L.M., P.C. Boxall, J. Englin and W. Haider. 2005a. Fly-In Angler's Valuation of Forest Management: An Analysis of Ontario Remote Tourism. Ecol. Econ. 53(1): 101-113.
Hunt, L.M., P.C. Boxall, J. Englin and W. Haider. 2005b. Forest harvesting, resource-based tourism and remoteness: an analysis of northern Ontario's sportfishing tourism. Can. J. For. Res. 35(2): 401-409.

Hunt, L.M., W. Haider, P.C. Boxall, J. Englin and S. Browne. 2002. Highlights of Ontario's non-road accessible resource-based tourism industry with emphasis on the fishing product. (Ont. Min. Natur. Resour. Centre for Northern Forest Ecosystem Research, Thunder Bay, ON.) CNFER TR-009.

McKercher, B. 1992. Tourism as a conflicting land use: northern Ontario's outfitting industry. Ann. Tour. Resear., 19(3): 467-481.

Ontario Ministry of Natural Resources (OMNR). 1987. Timber Management Guidelines for the Protection of Tourism Values. Queen's Printer for Ontario, Toronto, ON.

. 2001. Management guidelines for forestry and resourcebased tourism. Queen's Printer for Ontario, Toronto, ON. 37 p. 2002. State of the forest report, 2001. Queen's Printer for Ontario: Toronto, ON.

Pannell Kerr Forster. 2003. The economic impact of tourism in Sunset Country, Ontario. PKF Consulting, Toronto, ON

Research Resolutions \& Consulting Ltd. 2003. An economic profile of resource-based tourism in Ontario. Queen's Printer for Ontario, Toronto, ON. 41 p.

Research Strategy Group. 1997. Northern remote tourism travel survey - 1996 summary report. Ont. Min. Econ. Devel. Trade Tour., Toronto, ON.

Rylander, R.D., D. Propst and T. McMurtry. 1995. Nonresponse and recall biases in a survey of traveler spending. J. Trav. Resear. 33 (Spring): 39-45.

The DPA Group. 1988. Fishing lodges and resorts in British Columbia: marketing and development initiatives - Summary Report. BC Min Tour Recr. Cult., Victoria, BC.

Topolinski, D. and L. Anderson. 1985. An economic survey of Manitoba's lodge industry. Dept. Fisher. Oceans, Winnipeg, MB. 59 p. 